\title{
Challenges of School Re-Entry among Learner-Mothers and Mitigation Strategies Instituted by Stakeholders in Schools in Masaiti District
}

\author{
Mufalo Mutau Setwin*, Kabeta Mabuku Rachel \\ Zambia \\ *Corresponding Author: Mufalo Mutau Setwin, Zambia

\begin{abstract}
This paper discusses challenges of school re-entry among learner-mothers and mitigation strategies instituted by stakeholders in Masaiti district. The study was conducted in selected secondary schools and their surrounding areas in Masaiti district on the Copper belt province of Zambia. Phenomenology and descriptive survey were used as research designs. The sample size for this study was 120 comprising 62 females and 58 males drawn from 4 secondary schools and their surrounding areas. 75 participants were randomly selected while 45 participants were purposively sampled. The qualitative data was thematically analysed while quantitative data was analysed using Statistical Package for Social Sciences software. The study revealed that learner-mothers faced many challenges both at school and in the community where they live and little was being done to mitigate their challenges. The concentration by stakeholders was mainly on the girls to re-enter school but not on whether they would be able to cope as learner-mothers. Based on the research findings therefore, the study recommends that schools, parents, the Ministry of General Education and other stakeholders should monitor these learners and enhance the mitigation measures to address challenges faced by learner-mothers both at school and in the community in order to improve their performance.
\end{abstract}

Keywords: School Re-entry, Learner-Mothers, Challenges, Mitigation Strategies, Stakeholders

\section{INTRODUCTION}

The Ministry of Education in Zambia introduced the school re-entry policy in 1997 which allowed school girls who fell pregnant to return to school after giving birth (Obonyo and Thinguri, 2015; MoE, et al., 2004). Studies have been conducted on the school re-entry and despite the presence of the policy teen mothers who re-enter school have continued to face many challenges in various communities and secondary schools (Ntambo \& Kabubi, 2017; Mweemba, 2014; Mwale, 2014; Mwansa, 2011; Sitali, 2009). These challenges have led to truancy and high school drop-outs among learner-mothers. The studies that have been conducted seem to have focused much on the fact that the pregnant girls go back to school after giving birth but not so much on whether the conditions are favourable for them to re-enter school and concentrate on their studies.

Consequently, the rationale behind this study was to examine the challenges girls who re-enter school after child birth face both at school and at home and also to find out whether there were strategies put in place by various stakeholders to mitigate these challenges faced by these adolescent mothers who re-enter school in order to enhance their learning and academic performance and to make the re-entry policy more meaningful than a mere academic exercise.

\subsection{Statement of the Problem}

There seem to be a knowledge gap in the studies conducted by various researchers above on whether stakeholders monitor and mitigate challenges learner-mothers face. This study therefore, sought to establish the challenges girls who re-enter school after child birth face both at school and in the community where they live as well as finding out whether there were any strategies instituted by schools, parents and other stakeholders in order to mitigate these challenges in order to enhance their learning and academic performance in the secondary schools in Masaiti district on the Copperbelt province of Zambia. 


\subsection{Purpose of the Study}

The purpose of this study was to investigate challenges of school re-entry among learner-mothers and to find out what mitigation strategies were instituted by stakeholders in schools in Masaiti district.

\subsection{Research Objectives}

- To establish the challenges faced by girls who re-enter school in secondary schools and in the community where they live.

- To find out whether there are strategies put in place by schools and parents to mitigate challenges faced by girls who re-enter school.

\subsection{Significance of the Study}

The significance of this study is that the findings may provide information to policy makers in the Ministry of General Education and other stakeholders to come up with further strategies which can be used to mitigate challenges faced by adolescent mothers who re-enter school in order to enhance their learning and academic performance. This study may also be useful as it will contribute new knowledge related to the re-entry policy and hopefully enhance its effectiveness.

\subsection{Theoretical Framework}

Life History Theory derived from the scientific principles of natural selection guided the study. Life history theory is a branch of ecology and evolutionary biology that aims to predict and explain the observed patterns in life histories of living organisms such as growth, survival and reproduction (Yampolsky, 2003). The theory believes that for natural selection to occur there must be three conditions which should be met (Rozman, 2015). The first condition is that there must be phenotypic variation within the population and phenotypic variation then, is the variability in phenotypes that exists in a population (Metzler, 2015). Therefore, phenotypic variation within the population is in line with Bandura (1971) in his observational theory who demonstrated that behaviours are acquired by watching another (the model, teacher, parent, mentor, and friend) that performs the behaviour. The second condition is that the phenotypic variation must be transmitted to offspring such as cultural behaviours that are learnt by people in different communities where they live. The third condition is that the phenotypic variation must produce offspring. Some phenotypes may produce more offspring than others in that the more the phenotype produces offspring, the better or fit it can adapt to the environment (Rozman, 2015).

\section{LITERATURE REVIEW}

Mweemba (2014) conducted a study on the challenges faced by teen-mothers who re-enter school in selected secondary schools in Kitwe district on the Copperbelt province of Zambia. The study revealed that teen-mothers faced school environment challenges, economic challenges and personal related challenges. The study recommended that there was need for the Ministry of General Education to adopt a holistic approach which does not dwell on changing girls' behaviours, but to change the attitudes in society so that girls are encouraged to stay in school. Also that the Ministry of General Education should reflect on and urge changes to the Policy to make it law to protect teen girls in schools. The study however differs with the current study in that his study was conducted in the urban set up while the current study was conducted in the rural and remote areas of Masaiti district. Additionally, the sample size for his study was too small as it comprised only 15 respondents hence not representative in nature. Furthermore, only one research instrument (interviews) was used during data collection. The researcher would have also used questionnaires. A questionnaire is a research instrument consisting of a series of questions and other prompts for the purpose of gathering information from respondents (Gillham, 2008). One advantage of this method of collecting data is that it gives greater anonymity; hence respondents are free to write their own ideas on the subject matter (Kumar, 2005).

Baa-Poku (2016) did a research on girls' re-entry into school after pregnancy in the Ashiedu Keteke sub-metro district in Ghana. The main objective of the study was to investigate the reasons why pregnant school girls decide to return or not return to school; and what could be done to encourage them to go back to the classroom after delivery. The study established that the decision and inability of student mothers to re-integrate into formal education and achieve their educational aspirations were 
influenced to a large extent by prevailing negative factors such as childcare responsibilities, poor economic background, and unsympathetic teachers and school mates. The study further identified the absence of specific guidelines to effectively execute the provisions of the directive as a constraint on the smooth implementation of the directive. The study recommended capacity building for key implementers of the directive and the preparation of a substantive policy with the required legal backing. But the study was inclined to basic schools only in urban schools unlike the current study which was done in rural and remote secondary schools. Besides, his study was purely qualitative but mixed methods were used in the current study where both qualitative and quantitative methods were integrated.

Karimi (2015) did a study on challenges experienced by young-mother learners upon re-entry to formal primary schools in one of the divisions of coastal region, Kenya. The aim of the study was therefore to find out how these young-mother learners experienced challenges associated with motherhood as learners and also looked at some ways that the young-mother learners used in order to cope with the challenges. It was evident that lack of the much needed financial, emotional and social support was a challenge for the young-mother learners in their coping with education successfully. But the study sample was limited to only two primary schools and only seven (7) respondents were sampled comprising four (4) young-mother learners, two head teachers and a director of rescue village hence not a representation of the larger population.

\section{Study Methodology}

\subsection{Research Design}

Phenomenological and descriptive survey approaches were used as research designs in this study. Mixed methods were employed in this study where both qualitative and quantitative methods were integrated because they enable researchers to collect, analyse, and integrate both quantitative and qualitative data in a single study (Creswell, 2013).

\subsection{Research Sites}

The study was conducted in four (4) selected secondary schools in Masaiti which is a rural district.

\subsection{Target Population, Sample Size and Sampling Procedure}

This study targeted administrators, teachers, learner-mothers and other pupils in government secondary schools, parents who have teen mothers and the Ministry of General Education official in Masaiti district. The sample size for this study was 120 comprising 62 females and 58 males drawn from 4 secondary schools and their surrounding areas. Consequently, 75 respondents were randomly selected while 45 participants were purposively sampled.

\subsection{Research Instruments, Data collection Procedure and Data analysis}

The study used mixed questionnaires and semi-structured interviews to collect data from respondents. The qualitative data for this study was analysed by grouping similar ideas together and later coded in order to come up with themes. Statistical Package of the Social Sciences (SPSS) software was used to analyse quantitative data. Concurrent procedures were used in which quantitative and qualitative data were integrated in order to provide a comprehensive analysis of the research problem (Creswell, 2003).

\subsection{Ethical Considerations}

Ethical considerations were taken into account such as seeking permission from relevant authorities from the University, Ministry of General Education and District Education Offices and taking into consideration issues of respondent's confidentiality and other basic research conventions.

\section{STUdy FINDINGS AND Discussion}

\subsection{Research Objective 1: To Establish the Challenges Faced by Girls who Re-Enter School in Secondary Schools and in the Community where they Live}

The findings of this study revealed that all the girls who re-entered school faced a number of challenges both at school and in the community where they live. 


\subsubsection{Learner-Mothers being Wives and Marketeers at the Same Time}

The study found that some of the learner-mothers faced the challenge of being wives, marketeers and pupils at the same time. This phenomenon was discovered during the research. Besides, 4 out of 16 learner-mothers were married and they said that it was difficult for them to look after their husbands and children at the same time and prepare for school. One of them said that:

"It is not easy for me to work up early in the morning prepare food for my child and my husband then come to school. Sometimes I fail to come to school because I become tired with house chores. When I am at school I have to think of what to eat when I knock off because my husband is not working."

Furthermore, another teen mother had this to say:

"When I knock off I have to rush home so that I go and sell vegetables at the market so that I feed my family since my husband is not working and this affects my concentration when I am in class."

The study revealed that learning and academic performance of school-age mothers who re-entered school were affected by the challenges alluded to above. Therefore, there was a suggestion from school administrators that relevant authorities should come to the aid of those married learner-mothers so that they can be retrieved from their matrimonial homes in order to enhance their academic performance.

\subsubsection{Child Care and Teenage Parenthood}

All the 16 learner mothers said that it was not easy for them to take care of their babies at a tender age. Similarly, 85 respondents who participated in the study also added that caring for the child \& being a young parent affected teen mothers in secondary schools. The responses came from parents, teachers, pupils and school administrators. Therefore, the current results are consistent with a study conducted by Mweemba (2014) where he found out that teen mothers faced challenges of child care and parenting among others. On the contrary to the current findings, the Philippine government through the Ministry of Health initiated an adolescent health insurance package with Phil Health which included a maternity care package and a newborn care package for adolescents. Besides, there were also efforts to provide comprehensive sexuality education to re-entrants, parenting skills and harnessing technology for access to Sexual and Reproductive Health information using social media (UNESCO, 2014).

Additionally, 9 learner-mothers said that the challenge of child care and teenage parenthood made some of their colleagues to drop out of school completely. Furthermore, 4 out of 16 teen mothers said that child care and parenting led to some of them not to attend classes regularly, reporting late for classes and sometimes being absent from school. In the same vein 3 out 16 teen mothers said that their parents and other family members were not supporting them in terms of child care. As a result of this challenge, their academic commitment was affected at large. One of them had this to say:

"When I tell my mother to look after my child when I want to come to school, she says that, "teine nakupele ipafu pakuti ndesunga umwana obe" (It's not me who impregnated you for me to look after your child).

\subsubsection{Community or Family Rejection}

The study revealed that community or family rejection affected adolescent mothers who re-entered school. This information came from 25 teachers and 16 parents who affirmed that community and family rejection strongly affected learning and academic performance of teen mothers in schools. The study revealed that some of the learner-mothers were chased away from home by their guardians. As a result of this, 2 out of 16 teen mothers said that they ended up getting into early marriages because they were chased away from home after they were discovered to be pregnant.

Additionally, one guidance and counselling teacher said that some parents stopped paying school fees for teen mothers. As a result of this, some teen mothers ended up getting married to their boy-friends so that they get school support. He also said that this aspect had made some of them to fall pregnant for the second time and others dropping out of school completely so that they could concentrate on their marriages. Besides, it was discovered that others run away from their parents and resorted to stay alone for fear of rebuke and retribution. The current findings conforms to those of Banda (2005), who found that majority of young single mothers ran away from home to live in rented small rooms in 
nearby places, others looked for shelter from well-wishers which lasted for only weeks or months due to hostile environments.

\subsubsection{Stigma and Discrimination}

The study revealed that 69 respondents who participated in the study indicated that pregnant school girls and school-age mothers who re-enter school faced stigma and discrimination which led to some of them perform badly at school. Thirty-five (35) out of 42 pupils responded that stigma and discrimination strongly affected teen mothers. Furthermore, one guidance teacher said that some pupils, teachers and administrators labelled teen mothers as bad behaved pupils. This revelation sits well with the study by Ncube and Mudau (2017) in Gwanda district, Zimbabwe where one head teacher had this to say on the returning student from maternity leave: "the policy benefits the individual but not the school nor the community because the returning student becomes a bad example among other students. This has a big impact on the learning environment, think of a situation where two or more students are visibly pregnant and remain in school until they go on leave; ultimately the pass rate goes down because of naughty individual students." As a result of such assertions, it was also discovered that pregnant girls and girls who re-entered school had inferiority complex, low-esteem and lacked confidence in themselves. In this regard, 7 out of 16 re-entrants said that they thought other learners were gossiping about them and they were also thinking that their peers looked down upon them due to their status. Therefore, this finding corresponds with the discovery by Malahlela (2012) in Ncube \& Mudau (2017) who reported that pregnant learners usually suffer from inferiority complex, low self- esteem and lack of confidence based on the thinking that others were laughing or gossiping about them hence limiting their association with their peers any more.

Similarly, Shaningwa (2007) adds that a report from a Namibian study indicated that teachers were making humiliating comments towards teen mothers saying; "Some of you are adult people and have children. You are not supposed to make noise" or "why should a mother allow such behaviour to happen in class?"

Additionally, 10 out of 16 teen mothers interviewed confessed that some people called them prostitutes and told them that they would never be married in future. This assertion is in line with the study conducted in Kenya where it was discovered that parent-pupils suffered discrimination as the community does not value or recognise them as they call them prostitutes. In the same study on community challenges in Meru, it was revealed that young teen mothers confessed that it became hard for one to get married as men would not accept someone else's child and saw it as a burden. The study also found that old men took them for granted and sexually abused them for small favours and that men demanded for unprotected sex just to punish them which in most cases led to unwanted pregnancies and sexually transmitted infections which were high among learner-mothers (Wanyama and Simatwa, 2011).

\subsubsection{Stress and Depression as a Result of Peer and Societal Pressure}

From the current study, it was revealed that 80 out of 93 participants said that learner-mothers get affected with stress and depression due to challenges they faced both at home and in school representing $86 \%$ of the total number of respondents. Some teachers said that most of the teen mothers who re-entered school ended up dropping out of school due to stress and depression resulting from the challenges they faced such as lack of financial support and poverty. Some pupils further stated that some of the teen mothers were performing badly at school, some reported late for classes and others ended up dropping out of school due to pressure which came from their bad experiences. The study revealed that some of the re-entrants were fending for themselves and took care of their babies as well. Furthermore, the research findings were that some of the teen mothers came from child headed families where some of them were regarded as bread winners. As a result of the situation, some of them had stress because of being overwhelmed with family pressure. These research findings therefore, correspond with those of Mweemba (2014) who found that stress and depression were challenges encountered by learner-mothers. Similarly, the study conducted by Boulden (2001) in Australia on estimates of the rate of teenage pregnancy, alludes to the fact that balancing the demands of family and school can cause many teen mothers to feel fatigued and generally stressed.

Furthermore, according to American Academy of Child and Adolescent Psychiatry, depression was common among pregnant teens and teen parents were also likely to subject their children to abuse and neglect because they feel overwhelmed by their unfair, ever-demanding roles as parents (Slocum, 2017). 


\subsubsection{The Challenges of Poverty}

The study revealed that re-entrants were affected by poverty. When participants were asked whether poverty affected the performance of adolescent mothers in school, $92 \%$ of them agreed to that effect. All the participants further said that poverty had led to some teen mothers to engage into promiscuity so that they earn a living. Some teachers and parents added that due to poverty, some girls got pregnant and had children without fathers which became a burden for teenage mothers. This finding is in agreement with that of Mutombo et al (2010) who in their study on "the review of the re-entry policy on ordinary learners in Zambia" found that high poverty levels and peer pressure were factors leading to teenage pregnancies. Some teachers further stated that some of the re-entered girls engaged into early marriages due to poverty. One parent also said that:

"I fail to look after my child who re-entered school because I am poor, not working and I do not have any child who can support me and the family. Its better I allow my child to be married so that she can be taken care of by her husband to reduce on my burden of looking after many children."

But the current findings contradicts the research done in Mexico where it was revealed that the Ministry of Education provided scholarships programme to young mothers and pregnant girls between the ages of 12 and 18 years and 11 months to enable them to remain in education (UNESCO, 2015). Consequently, the current finding implies that the Zambian government was not doing enough to alleviate poverty from rural families in Masaiti district.

\subsubsection{Verbal Abuse from Peers, Teachers, and Parents or Guardians}

According to the findings of this study, 60 out of 86 participants said that verbal abuse from friends, teachers, parents or guardians affected learner-mothers where learning and academic performance were concerned. In addition, teen mothers' experiences as discovered by the researcher are likened to the study findings done by Camfed (2013) in Malawi, where some girls faced hostility from their fellow classmates, who called them different names such as 'makolo inu' (you are parents) which had to be mediated by the School Based Committee (SBC), working with students to raise awareness of early marriage and early pregnancy and encourage empathy and support for the young mothers.

Furthermore, the current study revealed that verbal abuse contributed to absenteeism and low selfesteem among teen mothers. Some teen mothers further reported that some of their friends opted to leave their homes and cohabite with their boyfriends hence got into premature marriages too. As a result of this aspect, learning and academic performance was affected as well. This indication is similar to the findings of Ntambo and Kabubi (2017) who investigated on the challenges faced by girls who fall pregnant and re-admitted back to school in schools in Mpongwe district. It was revealed that teen mothers faced verbal abuse from peers and teachers especially females.

\subsubsection{Managing the Roles of a Mother and Demands of School}

The study findings were that teen mothers were affected with the challenge of managing the roles of a mother and demands of school. Therefore, 80 out of 88 participants representing $91 \%$ subscribed to the response that teen mothers who re-entered school faced the challenge of managing the roles of a mother and demands of school. The study revealed that parent-pupils had difficulties looking after their babies and balancing with school programmes since they were also still young. This finding is in line with Fennel and Anort (2008) who revealed that teen mothers or re-entry girls had their roles as mothers, daughters and learners which co-exist simultaneously and in conflict.

\subsubsection{Lack of Support from Teachers, Peers and Parents}

From the data collected, 74 out of 83 participants representing $89 \%$ of respondents said that teen mothers lacked moral, material and financial support from teachers, friends, parents and guardians respectively. The study revealed that the situation had contributed to a number of learner-mothers to drop-out of school and enter into pre-mature early marriages. In the same vein, 3 teen mothers interviewed attested to the fact that lack of material and financial support from their parents had contributed to them falling pregnant and getting into premature marriages hence having children at a tender age. Some of the teen mothers also revealed that they were attending school whilst coming from their husbands' homes. Additionally, the study revealed that three (3) interviewed re-entrants had more than one child each which was against school re-entry policy guidelines. In line with the 
views of parent-pupils, the study conducted by Mutombo et al (2010) in Zambia, found that lack of care and support from parents, both emotionally and financially was a social factor linked to teenage pregnancy. The situation of parents is likened to the assertion made by Akelle (2007) who confirmed that due to many challenges faced by parents, young girls will continue to either get married off at early ages or acquire informal jobs that can barely support them and continue the cycle of poverty.

\subsubsection{Lack of Counselling Services in Schools and the Community}

The study indicated that there was lack of counselling services in secondary schools. Fifty-one (51) out of 79 respondents said that schools were not providing counselling services to teen mothers. The revelation does not sit well with Jamaica Ministry of Education et al (2013) which stated that postintegration monitoring system was done by the ministry and school-age mothers were provided with counselling services, family planning services, parenting skills and other available support services. Furthermore, the current study findings disagrees with the finding of Baa-Poku (2016) who conducted a research in Ghana and found that schools had guidance and counselling units that provided counselling services for all students.

The current study further discovered that teen mothers were not being monitored by the relevant authorities to find out how they integrated with other learners in secondary schools and what challenges they encountered at school as well as their communities where they live. Additionally, it was discovered that there were no trained counsellors to offer counselling services to re-entrants in schools. In this regard, all the 4 school guidance and counselling teachers who were interviewed said that they were not qualified counsellors to handle counselling services in schools. This confession from school guidance teachers corresponds well with Kapenda (2012) in Namibia who found that while many schools had a specific female teacher who counselled girls on issues pertaining to sexuality, either a teacher formally assigned to play this role by the school management or someone who had taken the task out of her own initiative, none of the teachers had specific training in counselling skills, although some had attended workshops on the topic.

When the learner-mothers were asked to indicate if counselling sessions took place in their various secondary schools, all the 16 of them responded that they never received any counselling services before from guidance teachers. They further revealed that they were not even aware that there were such services in school because they did not even know the teachers who were responsible for counselling services

Therefore, there was a submission from parents that schools and communities should come up with community centres were teenage mothers would access various services such as child care and family planning services.

\subsection{Research Objective 2: To Find Out Whether there are Strategies Put in Place by Schools and Parents to Mitigate Challenges Faced by Girls who Re-Enter School}

\subsubsection{Strategies Put in Place by Schools}

From the data collected, most of the participants interviewed said that schools did not put in place some measures or strategies to mitigate challenges faced by re-entrants. In this regard, 26 out of 42 pupils, 18 out of 33 teachers, 11 out of 16 learner-mothers and 10 out of 16 parents subscribed to this response. The participants outlined some of the measures which were lacking but necessary for learner-parents' well-being in schools. One of them was that schools were not giving free education or putting learner-mothers on school bursaries and this aspect had led to truancy and school drop-outs in many cases. The current finding does not correspond with the finding of Bolton (2015) in Kenya where secondary education was nominally free for learner-mothers where the government paid for teaching while students' families funded transport, uniforms and meals.

Additionally, it was found that schools were not allowing teen mothers to go to school with their babies nearby so that they could breastfeed where necessary. On the contrary, in the City of York, United Kingdom, young parents under the age of 20 were allowed to leave at agreed times while at school in order to breastfeed their babies if the childcare centre was close to the school (Gaines, 2015). Similarly, the study conducted by Bolton (2015) in Kenya adds that, some schools allowed teen mothers to bring their children to school, given time to go home or attend to their sick babies. 
Besides, the study revealed that there was no support for the children of teen mothers in terms of material and financial support as well as pre-school services so that they could be provided with learning activities.

But when guidance teachers, head teachers and their deputies as well as the ministry of general education official were interviewed on some of the strategies schools provided to mitigate challenges faced by re-entrants, their response was that schools offered counselling services to learner-mothers but their responses were disputed by some pupils, teachers, parents and re-entrants themselves. Guidance teachers also said that schools offered sexuality education which was incorporated in various learning subjects. They also said that re-entered girls were offered school places so that they could continue with schooling and re-entrants agreed with guidance teachers on their submission.

\subsubsection{Strategies put in Place by Parents and Guardians}

The data collected from all participants interviewed in the study revealed that parents and guardians tried in mitigating some of the challenges re-entrants faced at school and in the community. In this regard, some parents and guardians had the responsibility of taking care of teen mothers' babies while their mothers were learning. Child care was found to be one of the biggest challenge re-entrants faced. Therefore, some parents took that responsibility of baby-sitting so that teen mothers' burden could be reduced. Besides, it was also found that they encouraged teen mothers to continue with education so that they become self-reliant in future. Furthermore, parents and guardians also enrolled children of teen mothers at primary and pre-schools so that they could acquire education as well.

Additionally, the study findings were that parents were responsible for offering counselling services to young mothers on parental care and dangers of being a teenage mother. They also provided financial and material support to teen mothers as most of the boys and men who impregnated them had deserted them. Some of the culprits were also under the custody of their parents since they were also still too young to take full responsibility of parenthood. One parent said that he had even sued his son-in-law for lack of maintenance of his child at the local court but no support had come forth despite the step taken. He further lamented poverty levels being experienced in the district to be one of the factors leading to failure by culprits to provide financial support to their children. Due to the prevailing situation, most parents and guardians of teen mothers who re-entered school had no option but to offer material and financial support to both teen mothers and their children.

The current study findings on various kind of support provided by parents and guardians to learnermothers in Masaiti district corresponds with the study conducted by Lima (2016) in Rio de Janeiro, Brazil where adolescent mothers received support from their family members who paid for their school fees, took care of their babies while they were at school learning. Similarly, the current research findings are in agreement with Sriyasak (2016) who found that learner-mothers in Thailand received support from families in terms of child care, emotional, physical, financial and material support.

\section{CONCLUSION}

The study concluded that learner-mothers faced a number of challenges both at school and in the community where they live. These challenges were; poverty, lack of counselling services in schools, lack of financial, moral, spiritual and material support, the challenge of managing both the roles of a young mother and demands of school, stigma and discrimination, being teen wives, marketeers and being pupils at the same time among others. The established challenges in the study contributed to truancy, school drop-outs, early marriages, second pregnancies and poor academic performance among parent-pupils contrary to the objectives of the school re-entry policy.

\section{RECOMMENDATIONS}

Based on the findings, the study recommends that the Ministry of General Education and Department of Social Welfare need to establish measures that will help to monitor the learner-mothers and enhance mitigation strategies that will help to alleviate the challenges faced by these mothers. Stakeholders should also collaborate to offer bursaries to these girls; also strengthen the guidance and counselling services in schools so that the adolescent mothers are fully equipped with relevant information on sexuality education and other life matters. The government should set up day care facilities and learner-mothers should be allowed to breast feed their babies during break intervals. The 
stakeholders should also sensitise communities on the importance of education and step up measures to retrieve teenagers from early marriages.

\section{REFERENCES}

[1] Akelle, W. (2007). Journalism for development. School re-entry policy, http//journalismfordevelopment. blogspot.com/2007/02

[2] Baa-Poku, J. (2016).Girls' re-entry into school after pregnancy in the Ashiedu Keteke sub-metro district. MA Dissertation in Social Policy. Accra: University of Ghana.

[3] Banda, I. (2005). Parents' perception of teenage pregnancy. MA. Dissertation. Lusaka: University of Zambia.

[4] Bandura, A. J. (1971). Analysis of modelling processes. In A. Bandura (Ed.), Psychological modelling: Conflicting theories (pp. 1-62). Chicago: Aldine.

[5] Bayona, I. \& Kandji, M. (1996). Botswana's pregnancy related policies and their implications on expregnant girls' education and productivity. Abridged research reportNo.16. Nairobi: Academy science publishers.

[6] Bolton, L. (2015) HEART, Health and Education Advice \& Resource Team, Helpdesk Report: Education for pregnant girls and young mothers. Published online, Available from: http://www.heartresources_org. [Accessed on $14^{\text {th }}$ April, 2018]

[7] Boulden, K. (2001). Estimates of the rate of teenage pregnancy in Australia vary association of women educators. Available from: http://www.abc.net.au/plunton/resources.htm-13k.[Accessed on 14th April, 2018]

[8] Camfed, (2013). Theory of Change Case Studies, Back to School Campaign: Girls not Brides. Malawi: Camfed.

[9] Creswell, J. W. (2013). Steps in Conducting a Scholarly Mixed Methods Study. Thousand Oaks, CA: Sage Publications.

[10] Creswell, J. W. (2003). Research Design Qualitative, Quantitative, and Mixed Methods Approaches. Thousand Oaks, CA: Sage Publications.

[11] Fennel, L. \& Mc Anort. (2008). Decent ring Hemogemonic gender theory; the implications for educational research, compare: A journal of comparative and international education, 38(5) p.525-538.

[12] Gaines, A. (2015). Education and Support for Pregnant Students and School Age Parents. London, City of York: City of York Council.

[13] Gillham, W. (2008).Guidance and counseling. New Delhi: National council of family issues. Journal of Applied School psychology, 22(1), 69-85.

[14] Karimi, E. W. (2015). Challenges Experienced by Young-Mother Learners upon Re-entry to Formal Primary School: A case in one of the Divisions of Coastal Region, Kenya. Master's Thesis, Master of Philosophy in Special Needs Education: University of Oslo.

[15] Kumar, R. (2005). Research Methodology A Step- By-Step Guide for Beginners. London: SAGE Publications.

[16] Lima, T. N. F. A., et al. (2016). Social support networks for adolescent mothers, Journal of Nursing. 10(6), p. $4741-50$.

[17] Jamaica Ministry of Education, et al. (2013). National Policy, Reintegration of School-Age Mothers into the Formal School System. Jamaica: MOE Jamaica.

[18] Kapenda, H. M. (2012). An Assessment of the Implementation of the Re-entry Policy for Girls in Six Countries. The Case of Namibia, Windhoek: FAWENA.

[19] Lima, T. N. F. A., et al. (2016). Social support networks for adolescent mothers, Journal of Nursing. 10(6), p. $4741-50$.

[20] Ministry of Education, et al. (2004). Guidelines for The Re-entry Policy: What happens if a School-Girl fall Pregnant? Lusaka: MoE.

[21] Metzler, K. (2015). Phenotypic Variation: Definition \& Explanation. Retrieved from: https://study.com/ academy/lesson/phenotypic-variation-definition-lesson-quiz.html. [Accessed on $20^{\text {th }}$ January, 2019

[22] Mutombo, N. \& Mwenda, M. (2010). Review of the Re-Entry Policy. Lusaka: Ministry of Education Approaches. Nairobi: Acts Press.

[23] Mwale, S. (2014). Is Re-entry Policy Working? Times of Zambia Newspaper. Available from: http://www.times.co.zm/?p=47042 [Accessed on $6^{\text {th }}$ April, 2018]

[24] Mwansa, A. (2011). Re-Entry to School after Giving Birth: An Evaluation of the Process Used to Design and Implement Policy in Zambia. CREATE PATHWAY TO ACCESS: Research Monograph No.70. 
Consortium for Research on Educational Access, Transitions \& Equity. Retrieved from: rpc.org/pdf documents/PTA70.pdf.[Accessed on $6^{\text {th }}$ April, 2018]

[25] Mweemba, G. M. (2014). Challenges Faced by Teen-mothers Who Re-enter School in selected Secondary Schools on the Copperbelt Province of Zambia. MA Dissertation in Educational Psychology. Lusaka: UNZA.

[26] Ncube, D. \& Mudau, T. J. (2017). 'Legalising the illegal' interrogating the policy that allows pregnant school girls to go for maternity leave and come back to school. A case of selected secondary schools in Gwanda district. Global Journal of advanced research. 4 (2), p. 67-78.

[27] Obonyo, S. A \& Thinguri, R. W. (2015). A critical analysis of the extent to which the education policy on re-entry of girls after teenage pregnancy has been implemented in Kenya. Research journali's Journal of Education, 3(4).

[28] Rozman, A. (2015). "Life History Theory and School-Age Pregnancy: Review and Application". Honors Scholar Theses. 425. Available from: http://digitalcommons.uconn.edu/srhonors_theses/425. [Accessed on 7th April, 2018]

[29] Shaningwa, L. M. (2007). The educationally-related challenges faced by teenage mothers on returning to school: a Namibian case study. Doctoral dissertation, Rhodes University Available from: http://eprints. ru.ac.za/1646/). [Accessed on $26^{\text {th }}$ February, 2019]

[30] Sitali, M. N. (2009). The Effectiveness of the Re-entry Policy in selected High Schools of Kabwe district, MA Dissertation in Educational Administration. Lusaka: UNZA.

[31] Slocum, M. (2017). Problems Faced by Teen Parents. March of Dimes. Available from: https://www. livestrong.com/article/146370-the-problems-faced-by-teen-parents [Accessed on $17^{\text {th }}$ December, 2018].

[32] Sriyasak, A. (2016).Becoming a Thai Teenage Parent. PhD dissertation. Sweden: Mälardalen University Press.

[33] UNESCO, (2014) Developing an education sector response to early and unintended pregnancy. Discussion document for a global consultation. Available from: https://unesdoc.unesco.org/ark:/48223/pf00002 30510. [Accessed on $26^{\text {th }}$ February, 2019]

[34] UNESCO, (2015). Addressing early and unintended pregnancy. Available from: http://hivhealthclearing house.unesco.org[Accessed on $26^{\text {th }}$ February, 2019]

[35] Wanyama, E. G. A. \& Simatwa, E. M. W. (2011). Prospects and Challenges in the implementation of the Re-entry Policy of girls in secondary Schools in Kenya: A case study of Emuhaya District. Nairobi: Kenya.

\section{AUTHORS' BIOGRAPHY}

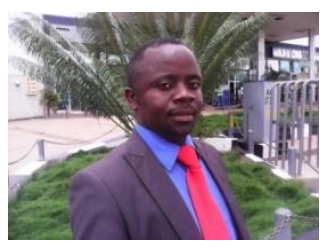

Setwin Mutau Mufalo, is a Head of Department Social Sciences at Mishikishi secondary school, he holds a bachelor's degree in Civic Education. He has 15 years of teaching experience. He has just completed his Masters degree in Civic Education \& Transformative Leadership at Mulungushi University in Kabwe. He has been admitted to pursue his Doctor of Philosophy $(\mathrm{PhD})$ degree in Civic Education with the University of Zambia.

Rachel Mabuku Kabeta, holds a PhD (Education Administration), has 29 years teaching experience in secondary school, teacher training at college and university level. She specializes in teaching and research in Education Administration, Management and Leadership. She is currently a lecturer at Mulungushi University in the School of Education.

Citation: Mufalo Mutau Setwin, Kabeta Mabuku Rachel. "Challenges of School Re-Entry among LearnerMothers and Mitigation Strategies Instituted by Stakeholders in Schools in Masaiti District". International Journal of Humanities Social Sciences and Education (IJHSSE), vol. 6, no.9, 2019, pp. 73-82. doi: http://dx. doi.org/10.20431/2349-0381.0609008.

Copyright: (1) 2019 Authors. This is an open-access article distributed under the terms of the Creative Commons Attribution License, which permits unrestricted use, distribution, and reproduction in any medium, provided the original author and source are credited. 